\title{
A rare cause of stricture and ulcer in the colon: Chronic graft versus host disease
}

\author{
Kolonda nadir bir darlık ve ülser nedeni: Kronik graft versus host hastalığı
}

\section{(D) Orhan COŞKUN¹', (DDeniz YILMAZ², (D) Fatma Zeynep ÖZEN², (D Mustafa ÇAPRAZ³}

Departments of ${ }^{1}$ Gastroenterology, 2 Pathology and ${ }^{3}$ Endocrinology, Amasya University, Sabuncuoğlu Şerefeddin Training and Research Hospital, Amasya

\section{Dear Editor;}

Often during routine gastroenterology examinations, ulcers and strictures in the colon and small intestine are encountered in patients. Differential diagnosis of ulcers in these patients may not always be easy. Graft-versushost disease (GVHD) is a serious complication that can be life-threatening after allogeneic bone marrow transplantation (1). Since the introduction of modern immunosuppressive treatment regimens, clinical symptoms, radiographic and histological findings are rarely seen in chronic graft-versus-host disease (CGVHD) (2). However, CGVHD patients often present with various gastrointestinal symptoms such as esophageal reflux, dysphagia, bloating, weight loss, and diarrhea (2). Edema, erythema, diffuse polypoid lesions, multiple ulcers, and strictures in the mucosa can be observed in the endoscopic examination of intestinal GVHD (3).

We present a patient who was diagnosed with CGVHD in a colonoscopic examination performed for iron deficiency anemia.

A 52-year-old female patient was referred to our gastroenterology outpatient clinic for endoscopic examination after the laboratory tests revealed iron deficiency anemia. The patient's medical history revealed that she had undergone autologous stem cell transplantation in 2012 and allogeneic stem cell transplantation in 2016 with a diagnosis of Non-Hodgkin lymphoma. A hysterectomy had been performed due to myoma.

When the patient's complaints were questioned, there were no gastrointestinal complaints such as bloating, constipation, diarrhea, or abdominal pain. Physical examination revealed multiple psoriasis colored rashes on the skin on the neck and nape (Figure 1). White blood cell count in laboratory tests: $8920 \times 10^{3} / \mu \mathrm{L}$, platelet: 470 x103/ $\mathrm{LL}, \mathrm{Hgb}: 10.9 \mathrm{~g} / \mathrm{dl}$, aspartate aminotransferase: 47 $\mathrm{U} / \mathrm{L}$, alanine transaminase: $39 \mathrm{U} / \mathrm{L}$, alkaline phosphatase:

Correspondence: Orhan Coşkun, Amasya University Sabuncuoğlu Şerefeddin Training and Research Hospital, Gastroenterolgy Division, Amasya, Turkey • Phone: +90 3582184000

Fax: +90 $3582120001 \cdot$ E-mail: drcoskunorhan@gmail.com
$99 \mathrm{U} / \mathrm{L}$, total bilirubin: $0.56 \mathrm{mg} / \mathrm{dl}$, albumin: $4.2 \mathrm{~g} / \mathrm{dL}$, serum iron: $115 \mathrm{u} / \mathrm{dl}$, total iron-binding capacity: $274 \mathrm{u} /$ dl, ferritin: $12 \mathrm{u} / \mathrm{L}$, vitamin B12: $353 \mathrm{ng} / \mathrm{L}$ were detected.

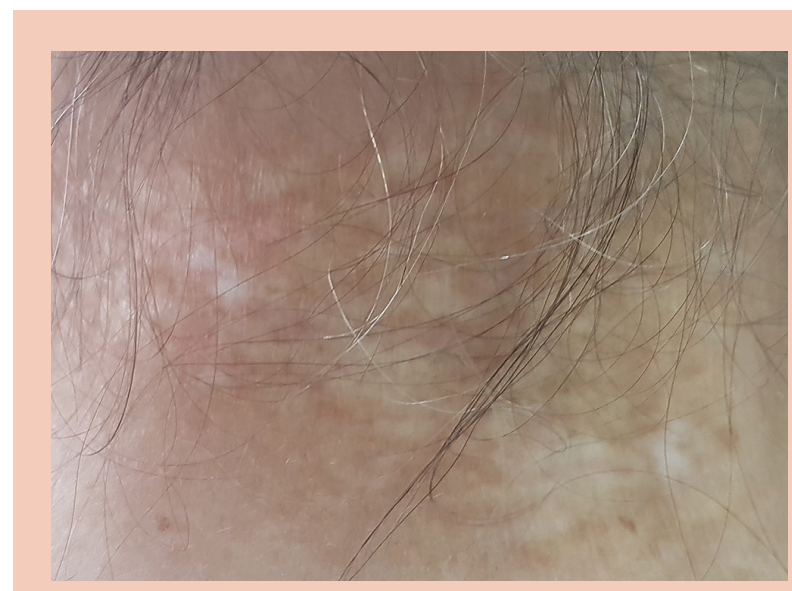

Figure 1. Multiple psoriasis colored rashes on the patient's skin.

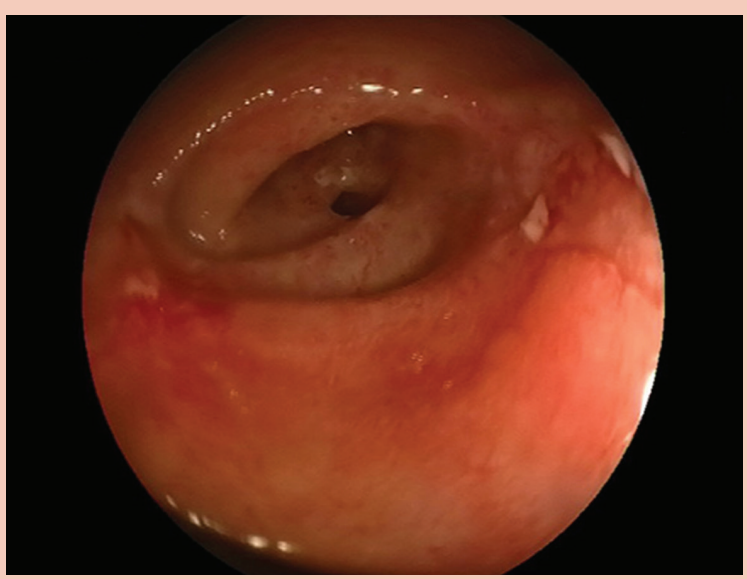

Figure 2. On endoscopic examination, the lumen of the colon was narrowed fibrotic, and exudate ulcers were observed proximally.

Coşkun O, Yılmaz D, Özen FZ, et al. A rare cause of stricture and ulcer in the colon: Chronic graft versus host disease. The Turkish Journal of Academic Gastroenterology 2021;20:127-128. DOI: 10.17941/agd.980428 


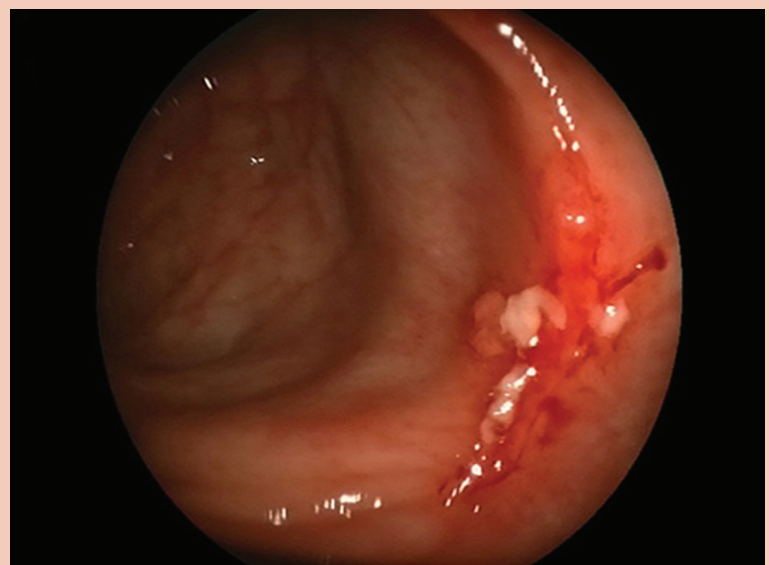

Figure 3. Fibrotic shrinkage and ulcer extending perpendicular to the lumen in the colonoscopic examination.

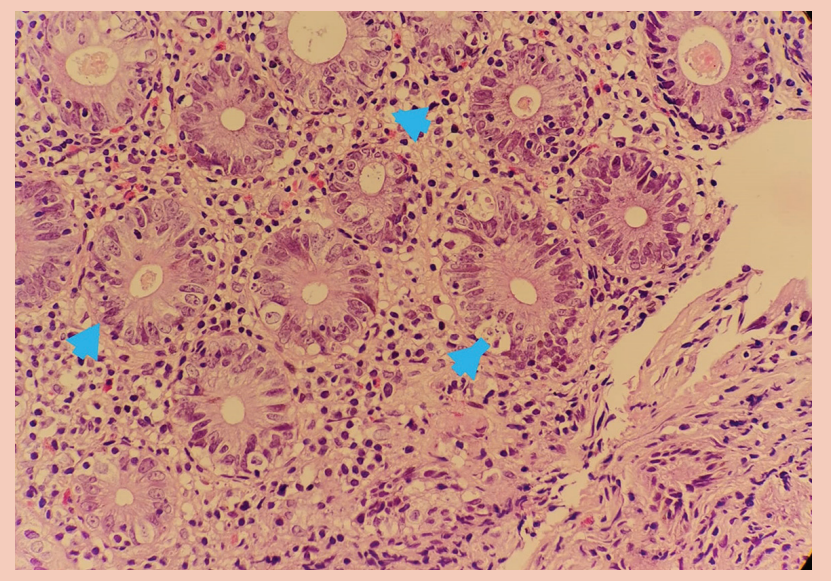

Figure 4. In biopsies taken from ulcerated lesions in the colon; Intense inflammation in the lamina propria and apoptosis in the crypts were observed (Blue arrows).
The colonoscopic examination showed that, in the ascending colon, the lumen was narrowed fibrotically, not allowing the endoscope to pass proximally (Figure 2 ). In addition, multiple ulcerated lesions extending perpendicular to the lumen, covered with white exudate, causing shrinkage in the mucosa, and approximately 5-6 mm diameter were observed in the ascending colon, transverse colon, and descending colon (Figure 3). In the pathological examination of the biopsies taken from the lesions, the patient was diagnosed with CGVHD after intense inflammation in the lamina propria. Apoptosis in the crypts was observed, and cytomegalovirus (CMV) was excluded (Figure 4).

Endoscopic images of GVHD-induced gastrointestinal involvement vary, and the involvement of lesions may be focal or diffuse $(4,5)$. Various lesions such as mild mucosal erythema, edema, prominent ulcers, lytic mucosal lesions can be seen in the upper and lower gastrointestinal tract (GIS) in endoscopic evaluation. The demonstration of apoptosis is very supportive for diagnosis. The diagnosis of gastrointestinal GVHD is made by endoscopic examination and mucosal biopsy, in the endoscopic biopsy (3). Other causes of apoptotic colopathy, especially CMV, should be considered in the differential diagnosis. Thus, chronic GVHD should be considered in the differential diagnosis of strictures and ulcers in a colonoscopic examination.

Conflicts of interest: All authors declare that there is no conflicts of interest.

\section{REFERENCES}

1. Carvalho JR, Lopes J, Carrilho-Ribeiro L, Tato Marinho R. A case of colonic graft-versus-host. GE Port J Gastroenterol 2019;26:456-7.

2. Akpek G, Chinratanalab W, Lee LA, et al. Gastrointestinal involvement in chronic graft-versus-host disease: a clinicopathologic study. Biol Blood Marrow Transplant 2003;9:46-51.

3. Ross WA, Couriel D. Colonic graft-versus-host disease. Curr Opin Gastroenterol 2005;21:64-9.

4. Iqbal N, Salzman D, Lazenby AJ, Wilcox CM. Diagnosis of gastrointestinal graft-versus-host disease. Am J Gastroenterol 2000;95: 3034-8.

5. Ponec RJ, Hackman RC, McDonald GB. Endoscopic and histologic diagnosis of intestinal graft-versus-host disease after marrow transplantation. Gastrointest Endosc 1999;49:612-21. 